\title{
The Interaction of Formal and Informal Contracts in the Decision of Cooperation of the Agents
}

\author{
Tatiana Iwai ${ }^{\dagger}$ \\ INSPER
}

\begin{abstract}
Given the existent risk of opportunism in transactions, formal and informal contracts play a central role in the decision of cooperation of the agents. The study aimed to compare the effectiveness of formal and informal contracts in the decision of cooperation of the agent and also to investigate their joint effects of substitution or complement on the cooperation of the agents. For that, an experiment was performed to test in a laboratorial environment the behavior of agents under the pressure of both contracts. The results of the experiment showed that informal contracts are more effective to guarantee cooperation among agents. Furthermore, formal and informal contracts can be used as substitutes or complements according to the order in which they are applied. When formal contracts precede informal ones, there is an increase in cooperation levels among agents.
\end{abstract}

Keywords: Cooperation. Formal contracts. Informal contracts.

\footnotetext{
* Author for Correspondence:

$\dagger$. Doctor in Business Administration EAESP/FGV

Institution: Clinical professor at INSPER

Address: Rua Quatá, n. 300, Vila Olímpia, São

Paulo - SP - Brazil - CEP 04546-042.

E-mail: tatianai@insper.edu.br

Telephone: +55 (11) 4504-2720
} 


\section{INTRODUCTION}

n 1968, Garrett Hardin published in Science his famous article "Tragedy of the T Commons". In this essay, the author describes a dilemma involving herdsmen and a pasture open to all. As every herdsman has a direct benefit for each animal added to his herd and the effects of overgrazing are shared by all the herdsmen; each of them, acting rationally, will tend to keep as many cattle as possible on the commons, until the

pasture is completely destroyed, leading all agents to a situation of complete disaster.

The situation described by Hardin illustrates how the interest of an individual is not necessarily tuned with the common interest, and the decision to act often involves a conflict between maximizing either the individual or the group's interest. On a public level, tax evasion, the destruction of natural resources, among other issues, are all problems of the same sort. On a private level, the stability of cooperative arrangements among firms is constantly threatened by the tension resulting from the need to invest resources in joint projects whilst concurrently protecting themselves from the opportunistic risks of their counterparty seeking private gains in detriment of collective value creation (ZENG; CHEN, 2003; AGARWAL; CROSON; MAHONEY, 2010).

All of these situations pertain to a general class of problems in which literature denominates as social dilemmas. Such are the situations in which the quest for individual rationality leads to a collective irrationality: the individual is encouraged into adopting a noncooperative behavior, benefiting from the good that is offered without having to incur with the costs for its provision. Nonetheless, the aggregated outcome derived from individual noncooperative decisions is a situation in which everyone is worse off (KOLLOCK, 1998; DAWES; MESSICK, 2000).

Within this context, we observe the intensive use of formal contracts in order to constrain and to guide the action taken by the agent towards the desired direction. Within the organizational domain, formal monitoring and sanctioning systems are solidly applied as productiveness and efficiency tools. However, despite the broad dissemination of these formal coercive systems, assorted criticisms are made towards their outcomes and the unexpected consequences resulting from its use (TENBRUNSEL; MESSICK, 1999; GNEEZY; RUSTICHINI, 2000; FEHR; SCHMIDT, 2007). Counterproductive effects within organizations such as a lack of trust, intrinsic motivation breakdown and the increase of resentment and tension are usually pointed out by those observing the indiscriminate use of such systems (PFEFFER, 1994; CIALDINI, 1996). 
In addition to this particular skepticism regarding the actual effectiveness of these incentives, there are yet further studies pointing out that informal contracts may also be used as an alternative to achieve cooperation without incurring in the negative consequences of the formal regulatory systems. In an extensive study on institutions and collective action, Ostrom (1990) claims, for instance, that neither the constitution of a formal central authority that sanctions individuals' actions - the Leviathan - nor the privatization of common goods based on property rights are the only solutions to social dilemmas. Contrarily, empirical cases reveal that individuals are indeed capable of being self-organized, based on the group's proposition of joint strategies and the consequent commitment to fulfill them. In other words, the author points out the use of informal contracts as a possible tool to leverage the cooperation in social action.

Hence, nowadays, literature presents studies that indicate both the capacity of informal contracts to promote cooperation, as well as studies that mark out the use of formal contracts. Having begun this debate on the effectiveness of each contract (formal and informal), it is worth comparing the conformative strength of both in promoting cooperation, and along the same line, to investigate their interaction and joint effects.

Seen in these terms, the present study concentrates on comparing the impact that formal and informal contracts bear on the decision to cooperate in social dilemmas. Following the same vein, the research is concerned with investigating whether informal contracts can minimize non-cooperative behavior with either an even or lesser force applied by formal contracts, and in addition to that, to question whether the presence of informal contracts may substitute or complement formal contracts in the promotion of cooperation among agents. Thus, we intend to contribute with the investigation of the interaction and the joint effects of formal and informal contracts in the decision to cooperate.

\section{FORMAL AND INFORMAL CONTRACTS}

Over their frequent interactions, agents normally encounter sundry levels of uncertainty in their economic exchanges. Thus, given the doubt regarding the behavior of the counterparty and the subsequent risk of being exploited by them, the extensive use of mechanisms to constrain social action and mitigate uncertainty and opportunism issues is understandable.

According to North (1990), these mechanisms provide rules, restrictions and incentives and can be formal (rules, laws, constitutions) or informal (social norms, conventions, selfimposed codes of conduct). 
With regards to formal arrangements, according to Zenger, Lazzarini and Poppo (2002), it is rules that can be promptly observed, as written documents or rules that are determined and applied through formal positions, such as authority or ownership, including, therefore, explicit incentives and legally formal contractual terms.

Among formal arrangements, the formal contract is its most prominent form. Widely used to solve agency, control and uncertainty problems, it can be considered as one of the main mechanisms used by firms to protect themselves against possible opportunistic behavior from their partners (GULATI, 1995). As observed by Macaulay (1963), two core elements in its constitution allow this protection. First, it is the characteristic to rationally plan the transaction, whilst trying to foresee all possible future scenarios and contingencies. Second, it is the characteristic to establish the existence and the enforcement of potential legal sanctions, with the objective to lead to a desired performance, or at least to compensate for its noncompliance.

Thus, by detailing and agreeing as to what each side must deliver, the uncertainty regarding the partner's behavior is diminished (MELLEWIGT; MADHOK; WEIBEL, 2007). In addition, when specifying the legal sanctions for non-compliance to previously and formally agreed rules, earnings generated from an opportunistic behavior from one of the parties are reduced, and thus, the expected benefits of the transaction are increased (LAZZARINI; MILLER; ZENGER, 2004).

However, despite the importance of formal contracts, other authors emphasize how informal arrangements, such as social norms and unwritten codes of conduct, are heavily present in the governance of organizational exchanges and can be an alternative way to guarantee cooperation of the parties involved in the transaction (BAKER; GIBBONS; MURPHY, 2002). Zenger et al. (2002) define these as rules based on implicit understandings and for that, are rarely formalized by means of written documents. Thus, the scope of informal contracts comprises much less regulation from formal positions and is more closely associated to social norms, routines and political processes.

When discussing about trading relationships in Japan, for instance, Dore (1983) points out how the existence of informal arrangements enabled the weakening of business verticalization and the emergence of coordination of fragmented small firms. According to the author, this phenomenon was only made possible by the prevalence of moralized trading relationships of mutual goodwill, where each side recognizes its obligation to try to maintain the stability of the relationship. These successful organizational forms are supported not by 
the existence of a formal contract that impels constituent firms to adopt a cooperative behavior, but by a sense of duty that goes beyond the terms of the written contract and for a greater preference for high trust relationships in detriment of bargaining relationships.

One of the reasons for the effectiveness of informal contracts is the existence of the "shadow of the future", which generates the expectation of cooperation by the other agent, because the value of the future relationship can be considered great enough to discourage opportunistic behavior in the present by the fear of breaking down the relationship (Baker et al., 2002). Thus, the "shadow of the future" implies that broken promises today may lead to business losses in the future, removing as a consequence many of the incentives for opportunistic behavior today (CARSON; MADHOK; WU, 2006). In this way, as the shortterm opportunism may compromise long-term cooperation, the "shadow of the future" ends up encouraging strategic reciprocity: cooperation from one of the parties leads to cooperation by the other one, just as opportunism will be replied by retaliatory opportunism (Parkhe, 1993).

Laboratory research results corroborate indeed the importance of the "shadow of the future" within cooperation. Dal Bó (2005), for example, whilst simulating a infinitely repeated prisoner's dilemma game, found results that support the following argument: the greater the probability of iteration continuity amongst players, the greater the levels of cooperation achieved by the players.

Another informal element, which encourages cooperation is reputation. The firm is not singly concerned, most of the time, with the reaction of the counterparty involved in the ongoing exchange, but it is also aware of the impact that an inappropriate conduct can cause to its reputation, compromising its chances of finding future partners, and in doing so, reducing its long-term earnings. As a matter of fact, several experiments demonstrate how reputation is able to increase levels of cooperation (BOLTON; KATOK; OCKENFELS, 2004; BARTLING; FEHR; SCHMIDT, 2012). These studies show that even in one-shot games, the disclosure of the agent's past behavior appeared to be efficient in generating cooperation in transactions.

We have also to bear in mind the influence of social reciprocity in the effectiveness of informal arrangements (FEHR; FISCHBACHER, 2002; ROTH, 1995). According to Falk, Gatcher and Kovacs (1999, p. 254), this reciprocity is associated with the "non-strategic conditional willingness to reward kind acts (positive reciprocity) and to punish unkind ones (negative reciprocity), even if this is costly for the reciprocating subject". In this respect, 
social reciprocity is an intrinsic motivation to respond according to the other's action, even in the case of absent extrinsic incentives.

Finally, trust is another typical element of informal arrangements that sustains cooperation. Trust is seen as an expectation that involves the intention to accept vulnerability based upon positive expectations about the other's behavior, thereby minimizing the fear that the exchange partner would act in an opportunistic manner (ROUSSEAU et al., 1998). With this, trust plays a similar role to a formal contract when we refer to it making the behavior of the counterparty predictable (GULATI, 1995). This predictability is formed from repeated cooperative exchanges that write the relationship's story. Throughout the relationship, the parties can observe and test the existence of trust. As this trust is confirmed, cooperation predictability becomes more visible and taken for granted.

Thus, trust along with reputation, "shadow of the future" and social norms of reciprocity form the elements that work as informal contracts, minimizing opportunistic action and increasing cooperation levels among agents, even though contractual provisions may not be present.

Given the capacity of formal and informal contracts to generate cooperation, in order to compare the conformative strength of both, we have the following hypothesis:

Hypothesis 1: Informal contracts present a greater impact on the levels of cooperation of the agents than formal contracts.

Concerning the application of formal and informal contracts, an important discussion still surrounds their joint effects. Literature on this topic shows mixed arguments on the interaction between these contracts. On one hand, there are authors who advocate for the substitution effect in which the use of a type of contract will either weaken or make the other unnecessary (MALHOTRA; MURNIGHAN, 2002; FALK; KOSFELD, 2006; ZASU, 2007). On the other hand, other authors advocate for the complementary effect in which their joint use produces a positive effect on cooperation (POPPO; ZENGER, 2002). In an attempt to reconcile these positions, an alternative view has argued that they can be substitutes or complements according to some characteristics of the actual relationship between the parties (LAZZARINI et al., 2004; WOOLTHUIS et al., 2005; MELLEWIGT et al., 2007).

Following the line to understand some determinants within this joint effect, we can add to the discussion the development order of each type of contract in the relationship. The main 
argument is that the complementary or substitute effect depends on the contracts constitution order.

In the case of the formal contract as an antecedent to the informal one, there are two divergent positions regarding their joint effect. On one hand, some authors point out that the presence of formal contracts impairs the formation and operation of informal contracts due to two reasons: the emphasis on a detailed formal contract can signal mistrust, undermining the construction of a more positive relationship (SITKIN; ROTH, 1993); in addition, the resulting cooperation of formal contracts would be attributed to the contract itself (situational attribution) and not to the benevolence and integrity of the counterparty, which are important elements to increase the perceived trustworthiness of the other (FREY; JEGEN, 2001; MALHORTA; MURNIGHAN, 2002). With this, the presence of a formal contract would inhibit the formation of the informal contract.

On the other hand, other authors rebut this negative effect, for they advocate that even though the formal contract may weaken the intrinsic incentive to cooperate, this could be neutralized, because the formal contract discourages short-term opportunism (ZENGER et al., 2002). This is because, when diminishing earnings from short-term's opportunism by sanctions, formal contracts turn cooperative earnings from a long-term relationship comparatively more attractive and reinforce the incentive to cooperate from the "shadow of the future" (BAKER et al., 2002; LAZZARINI et al., 2004).

Thus, despite displacing the cause of cooperation from an intrinsic motivation to another extrinsic, the formal contract may be an important antecedent to the formation of the informal contract, especially in the initial stages of the relationship, when it is more vulnerable to opportunism and formal safeguards are important to allow that the parties will be willing to invest in the relationship.

In addition, when the formal contract precedes the informal one, the latter may refine the former's application even more. Given that the formal contracts are incomplete by the inability to predict all future contingencies, informal arrangements may compliment formal contracts in situations not addressed by contractual provisions or even in a failure of the actual regulatory system. In this line, informal arrangements refine the formal one, in so far as the first aggregates greater ability to coordinate and to adapt to the second (MELLEWIGT et al., 2007). Social norms, which support informal arrangements, promote not only flexibility norms, which facilitate the adaptation to unforeseen events, but also foster norms of solidarity that are essential for joint and bilateral resolution of problems in situations not predicted in 
the formal contract (POPP; ZENGER, 2002). With this, even when the formal contract is already established to protect the parties against opportunism, the development of the informal arrangement may yet increase cooperation by two main reasons: it mitigates the adaptable limits of the formal contracts by their social norms of mutualism and bilateralism, as well as facilitates joint resolutions of situations in which there are gaps or doubts in the interpretation of contractual clauses. Thus, we observe that when formal contracts precede the formation of informal ones, we can still expect a positive effect on the levels of cooperation among agents.

As for the case in which the informal contract precedes the formal one, complementary effects may no longer be observed. This is because it is argued that the existence of the informal contract substitutes and makes the subsequent constitution of the formal contract unnecessary (RING; VAN DE VEN, 1994). If norms of social reciprocity and trust are already configured as an effective safeguard against opportunism and can leverage cooperation, there would be no need of incurring in the costs of the formal contract. According to Gulati (1995, p.93), "where there is trust, people may not choose to rely upon detailed contracts to ensure predictability". In which case, when the informal contract has already stabilized cooperation among agents, the formal contract would add little to cooperation and it would configure just as a formalization of a commitment already existing between the collaborating parties.

Based on these arguments, we find that:

Hypothesis 2: The complementary effect between formal and informal contracts depends on the order of the constitution of the types of contracts.

\section{METHODOLOGY}

In Brazil, there are few studies that apply the experimental methodology in the field of organizations and strategy (SAUAIA; ZERRENNER, 2009; ANTIQUEIRA; SAES; LAZZARINI, 2007). However, with due regard to internal and external validity of the experiment, this methodology can provide a fertile basis for dialogue between theory and evidence. So, to test our hypotheses, we used an experiment based on the methodology of experimental economics.

The sample consisted of ninety subjects, who were drawn from the undergraduate program in business management and public administration from a business school in São Paulo. 
The experiment was programmed and run using the software Z-Tree (Fischbacher, 1999), a specialized platform for experimental economics games. Participants were randomly divided into groups upon arrival at the lab. No participant attended more than one session. Participants were paid in accordance with their performance in the game, at an exchange rate of 1 real (BRL) to 24 experimental tokens.

\subsection{EXPERIMENTAL DESIGN}

The experiment was based on a public good provision game for 30 periods. 15 experimental groups were formed with six participants allocated in each group. At each period of the game, each participant should make a decision between investing any amount of their endowment of 10 tokens in one of the two proposed accounts: a personal account (called P) or a group account (called G).

The amount invested in the P account belonged wholly and solely to the individual; the amount invested in the $\mathrm{G}$ account received a given interest rate (it was multiplied by an efficiency factor of 2.4) and was divided equally among all six members of the group. Thus, the payoff of each individual was the sum of the investment made in the account $\mathrm{P}$ and a share in the account $\mathrm{G}$. Thus, the payoff for each individual $i$ was given by:

$$
U_{i}=P_{i}+\frac{\sum_{j=1}^{n} G_{j} \times r}{n}
$$

where: $\mathrm{P}_{i}$ corresponded to the amount invested in the personal account by member $i, G_{j}$ was the amount invested in the $\mathrm{G}$ account by each member of the group, $\mathrm{r}$ corresponded to the efficiency factor on the contributions made in the group account $\mathrm{G}$ and; $n$ corresponded to the number of members in a group (in this case, six). In this game model, the dominant strategy was to allocate every token in the $\mathrm{P}$ account. However, the decision that reached the social optimum (Pareto efficiency) was to invest in the $\mathrm{G}$ account.

The experiment aimed to compare the effects of different types of contracts in the cooperative behavior of the agents. To operationalize the informal agreement, we used a motivational solution widely used in experiments - face-to-face communication. According to several authors (Ostrom, 1990; Ostrom; Walker; Gardner, 1992), communication can be a mechanism for observing not only agents' capacity to organize themselves, but also the force of social pressures and moral suasion as a conformative action mechanism. Therefore, the communication mechanism would enable precisely the manifestation of these social processes. However, if promises and words have little value or at least if they are not able to 
lead to cooperation at an optimum level, it would be worth using a formal agreement to reduce the uncertainty of exchanges and minimize the risk of opportunism in transactions.

To operationalize the formal contract, we used a structural solution also widely used in experiments - a formal and explicit incentive (punishment/reward) for cooperation. From these manipulations, four treatments have been developed:

\section{Treatment NC/NP: Non-Communication and Non-Punishment (control)}

\section{Treatment NC/P: Non-Communication and Punishment (formal contract only)}

Treatment C/NP: Communication and Non-Punishment (informal contract only)

Treatment C/P: Communication and Punishment (formal and informal contracts simultaneously)

Three sessions were developed in the experiment, where treatments were alternated as shown in Table 1. Each session had a total of 30 periods of the game.

Table 1 - Treatments per Session Type

\begin{tabular}{llll}
\hline & 1st Treatment & 2nd Treatment & 3rd Treatment \\
\hline Session 1 (5 groups) & $\mathrm{NC} / \mathrm{NP}$ & $\mathrm{NC} / \mathrm{P}(*)$ & $\mathrm{C} / \mathrm{P}(*)$ \\
\hline Session 2 (5 groups) & $\mathrm{NC} / \mathrm{NP}$ & $\mathrm{C} / \mathrm{NP}$ & $\mathrm{C} / \mathrm{P}$ \\
\hline Session 3 (5 groups) & $\mathrm{NC} / \mathrm{NP}$ & $\mathrm{NC} / \mathrm{P}(* *)$ & $\mathrm{C} / \mathrm{P}(* *)$ \\
\hline Note: $(*)$ Punishment-reward factor: $\mathrm{M}=0.5 ;(* *)$ Punishment-reward factor: $\mathrm{M}=2$.
\end{tabular}

The NC/NP treatment was a control treatment and, as such, it did not rely on any regulatory mechanism. Therefore, in this treatment, subjects were not allowed to communicate and discuss decisions made neither punish those who did not contribute in the group account $(\mathrm{G})$. In the NC/P treatment, we introduced a formal incentive for cooperation in the group account. Opportunistic behavior was punished by a fine, just as cooperative behavior was rewarded. This treatment aimed to observe the cooperation resulting from formal contracts. In the C/NP treatment, we introduced an informal mechanism for cooperation: face-to-face communication. This treatment aimed to observe the cooperation resulting from informal contracts. Finally, in the C/P treatment, both communication and punishment/reward were applied in order to measure the joint effect of formal and informal contracts on cooperation.

For all treatments, following each period, participants were informed of the total contributions made by the group in the account $\mathrm{G}$, their individual profit (profits earned both 
during the period as well as the accumulated one) and a history table with the subject's contributions and the group's mean contributions. Information about other's profits or their individual contributions in the account $\mathrm{G}$ were not provided.

The communication treatment worked as follows: for every three periods, the group members were allowed to discuss the proposed decision problem. The communication was recorded. It is worth noting that this mechanism did not change the monetary gains of each member of the group. Thus, we can consider the same utility function in our theoretical predictive analysis.

The formal incentive mechanism worked as follows: if the amount $G_{i}$ invested by the individual $i$ was smaller than the average investment $\mathrm{G}_{\mathrm{M}}$ in the group account $\mathrm{G}$, a fine was applied over this difference. If the amount $G_{i}$ was greater than the average investment $G_{M}$ in the group account G, a reward was applied over this difference. In session 1, the punishment/reward factor was $M=0.5$; in sessions 2 and 3, this factor was $M=2$. In both cases, the payoff was given by:

$$
U_{i}=P_{i}+\frac{\sum_{j=1}^{n} G_{j} \times r}{n}+\left(G_{i}-G_{M}\right) \times M
$$

where: $G_{i}$ was the amount invested in the $\mathrm{G}$ account by member i; $G_{M}$ was the average investment in the $\mathrm{G}$ account and; $M$ was the punishment/reward factor over differences between individual contributions and group's mean contributions in the account G.

In our game model, the dominant strategy was to invest each token in the individual account P. Even when the punishment/reward factor $M=0.5$ was introduced, the dominant strategy remained the same. Only when the punishment/reward factor was changed to $M=2$, the game equilibrium was altered and it was possible to promote Nash equilibrium in the social optimum and the dominant strategy was to contribute all the tokens in the G account.

\section{RESULTS}

In order to keep the symmetry in the three sessions, for the first 10 periods they all began without any regulation mechanism (T1 - NC/NP). In fact, the contributions means of the three sessions in the first treatment showed no significant differences (Kruskal-Wallis, $\mathrm{p}=$ $0.613)^{1}$. Over the 10 periods of the first treatment, we noticed a clear downward trend of cooperation, as shown in Figure 1. Period after period, the contribution level in the G group account was decreasing, which shows a possible strategic learning by the participants, who understood that the most rational individual strategy was not contribute to the group account, 
since the decision of non-cooperation was the one which paid the highest payoff, regardless of what other players decided to do.

In some periods of this treatment, we could observe an attempt to raise the levels of cooperation. This orientation can be understood as an effort to overcome the dilemma subjects were facing - although not contributing was the best possible decision, when all (or most) individuals did not contribute, the payoff of each one fell considerably. This explains this brief willingness to cooperate in an attempt to signal the need for everybody to contribute, which would lead to the best collective result. However, this short propensity to cooperate eventually faded away, once these "cooperative" players probably realized that they were only "spending" their tokens, while others players were free riding on their contributions.

Thus, as predicted by theory, in the absence of any regulatory mechanism that encourages the group to contribute, the agents were not able to solve the collective action problem they faced.

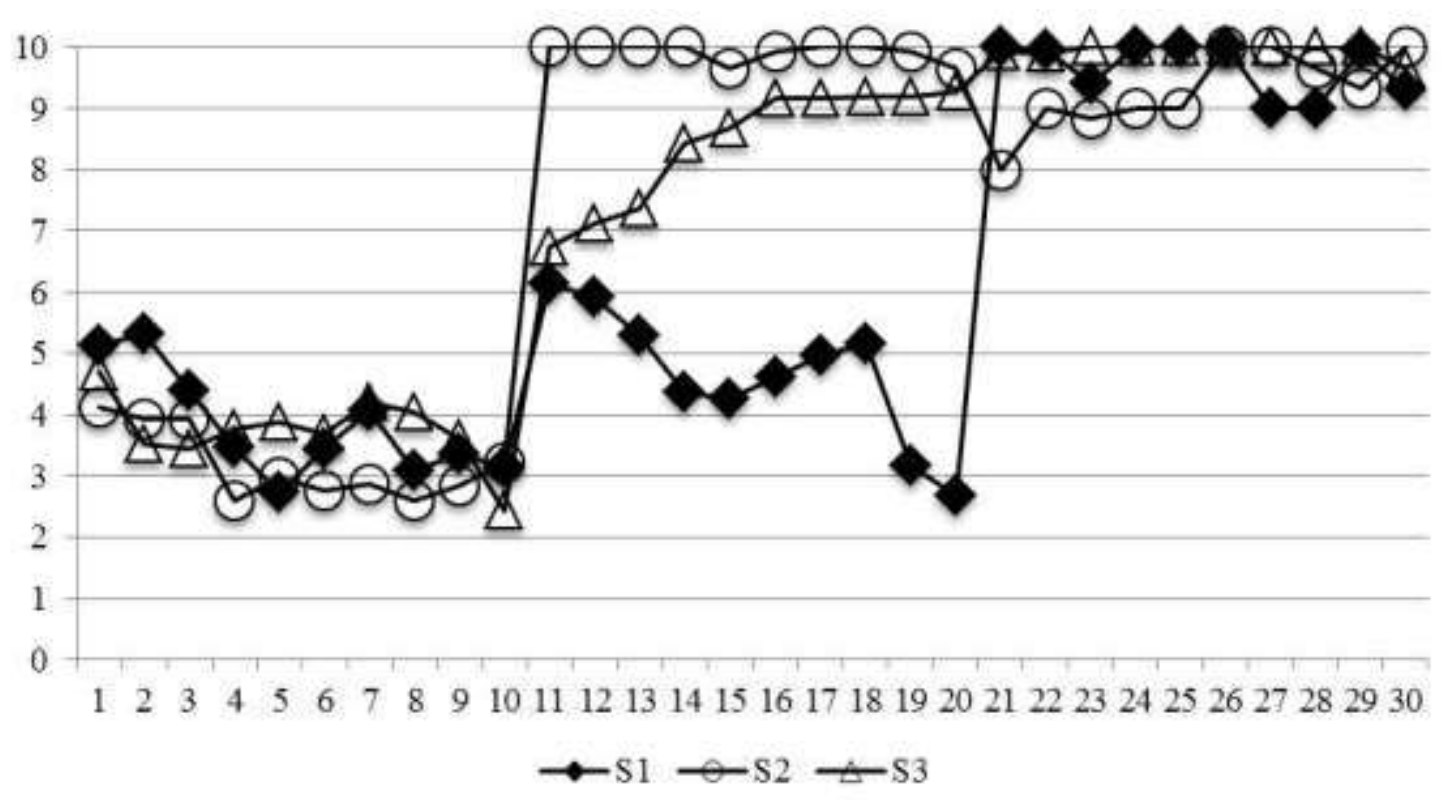

Figure 1: Contribution level in the G account Source: Research Data

In the 2nd treatment of session 1 (S1), from period 11 to 20 in Figure 1, the penalty/reward mechanism was introduced with an $\mathrm{M}=0.5$ factor being applied, which either penalized or rewarded the differences between individual and group contributions in the $G$ account. This factor was not strong enough to alter the non-cooperation equilibrium.

By comparing this treatment with the previous one, we can observe an increase in contributions means on the $\mathrm{G}$ account from 3.82 to 4.66, as shown in Figure 2. The difference between these means is significant (Wilcoxon, $p=0.043$ ). In Figure 1, it is also possible to 
notice this improvement on cooperation. But once again, the levels of cooperation have decreased over the periods of this treatment. This can be explained by the fact that the penalty-reward mechanism $(M=0.5)$ had no objective impact in the best decision for the dilemma, since non-cooperation was still the best course of action.

The improvement in cooperation levels can be attributed to the very signal provided by the formal mechanism. By punishing (even if by an "ineffective" manner) those who did not contribute and by rewarding those who cooperated, this penalty-reward factor may have made some players aware of the need for cooperation, even if it did not interfere with the dominant strategy, which was non-cooperation.

In the last treatment of this session $\mathrm{S} 1$ (from periods 21 to 30 ), $3^{\text {rd }}$ treatment (C/P $M=$ $0.5)$, in addition to the formal contract, we introduced the communication mechanism among participants. The inclusion of this mechanism presented a strong impact on players' decision, raising contributions levels from 4.66 to 9.66. The difference between these means is significant (Wilcoxon, $\mathrm{p}=0.043$ ). In Figure 1, it is possible to see clearly the positive effect of communication on cooperation levels throughout periods, where we can observe almost $100 \%$ contribution in several periods of this treatment.

This result can be attributed to the various motivational solutions that the communication mechanism is capable of creating. According to Kollock (1998), this mechanism provides participants the chance to make explicit commitments about what they will do. In addition, it also allows for moral suasion. And finally, it is able to create a sense of group identity, where social pressure, trust and social norms matter.

Session 3 (S3) presented the same sequence of treatments as in session 1(S1). However, in S3, the penalty-reward factor was 2. This factor was altering the non-cooperation equilibrium, so that contributing in the $\mathrm{G}$ account became the best individual rational choice. The impact in the decision is visible: contributions increased period after period (from periods 11 to 20 ) and the cooperation settled at a high level. The mean contribution in the $\mathrm{G}$ account increased from 3.73 (T1: NC/NP) to 8.43 (T2 NC/P M=2). The difference is significant (Wilcoxon, $\mathrm{p}=0.043$ ).

It is worth highlighting the difference in the results from the weak and strong sanction mechanisms (respectively applied in the $2^{\text {nd }}$ treatment in S1 and S3). Even though both sanctions have increased the levels of cooperation regarding the first treatment, when the sanction was weak ( $\mathrm{S} 1-\mathrm{M}=0.5)$, the level of cooperation appeared to be significantly lower 
(Mann Whitney, $\mathrm{p}=0.009$ ) than in the situation in which the sanction mechanism was strong $(\mathrm{S} 3-\mathrm{M}=2)$, according to Figure 2 (mean $\mathrm{S} 1_{\mathrm{T} 2}=4.66$ and mean $\mathrm{S} 3 \mathrm{~T}_{2}=8.43$ ).

In the last treatment of this S3 session, two mechanisms were applied: the penaltyreward $(M=2)$ factor and communication. We can observe, in Figure 1, an improvement in contributions in relation to the previous treatment (from 8.43 to 9.95) and this difference is significant (Wilcoxon $\mathrm{p}=0.043$ ). In addition, by comparing the variations of contributions between the $2^{\text {nd }}$ and $3^{\text {rd }}$ treatments, we notice that the variance of contributions in the $G$ account $\left(\mathrm{s}^{2}{ }_{\mathrm{T} 2}=0.972 \mathrm{~s}^{2} \mathrm{~T} 3=0.011\right)$ diminished in the last treatment with the application of the informal mechanism (Levene, $\mathrm{p}<0.001$ ), which suggests that this mechanism stabilized cooperation. With this, we observe, that with communication, the subjects contributed almost all their endowment in every period of this treatment.

In addition, when comparing the results from the $3^{\text {rd }}$ treatment (from periods 21 to 30 ) between sessions 1 and 3, we observe that there are no significant differences between the contribution means (Mann-Whitney, $\mathrm{p}=0.264$ ), signaling that the presence of the communication mechanism neutralized the differences of cooperation between the weak and strong sanctions found in the $2^{\text {nd }}$ treatment in between these sessions, according to Figure 2 (mean $\mathrm{S} 1_{\mathrm{T} 3}=9.66$ and mean $\left.\mathrm{S} 3_{\mathrm{T} 3}=9.95\right)$.

In session 2 (S2), we reversed the inclusion order of the penalty - reward and communication mechanisms. As previously observed, in the $1^{\text {st }}$ treatment $(\mathrm{NC} / \mathrm{NP})$, the cooperation levels were as low as in other sessions (mean $=3.19$ ), showing that in the absence of any regulation mechanism, the agents are not able to solve the dilemma they are facing. In the $2^{\text {nd }}$ treatment $(\mathrm{C} / \mathrm{NP})$, we can observe as the communication mechanism considerably leveraged the level of cooperation (from 3.19 to 9.92). This difference is significant (Wilcoxon, $\mathrm{p}=0.043$ ). In addition, this contribution mean in $\mathrm{T} 2$ is greater than that presented both in the weak sanction mechanism (Mann-Whitney, $\mathrm{p}=0.007$ ) as for the strong sanction one (Mann-Whitney, $\mathrm{p}=0.007$ ), as shown in Figure 2. These results support H1. 


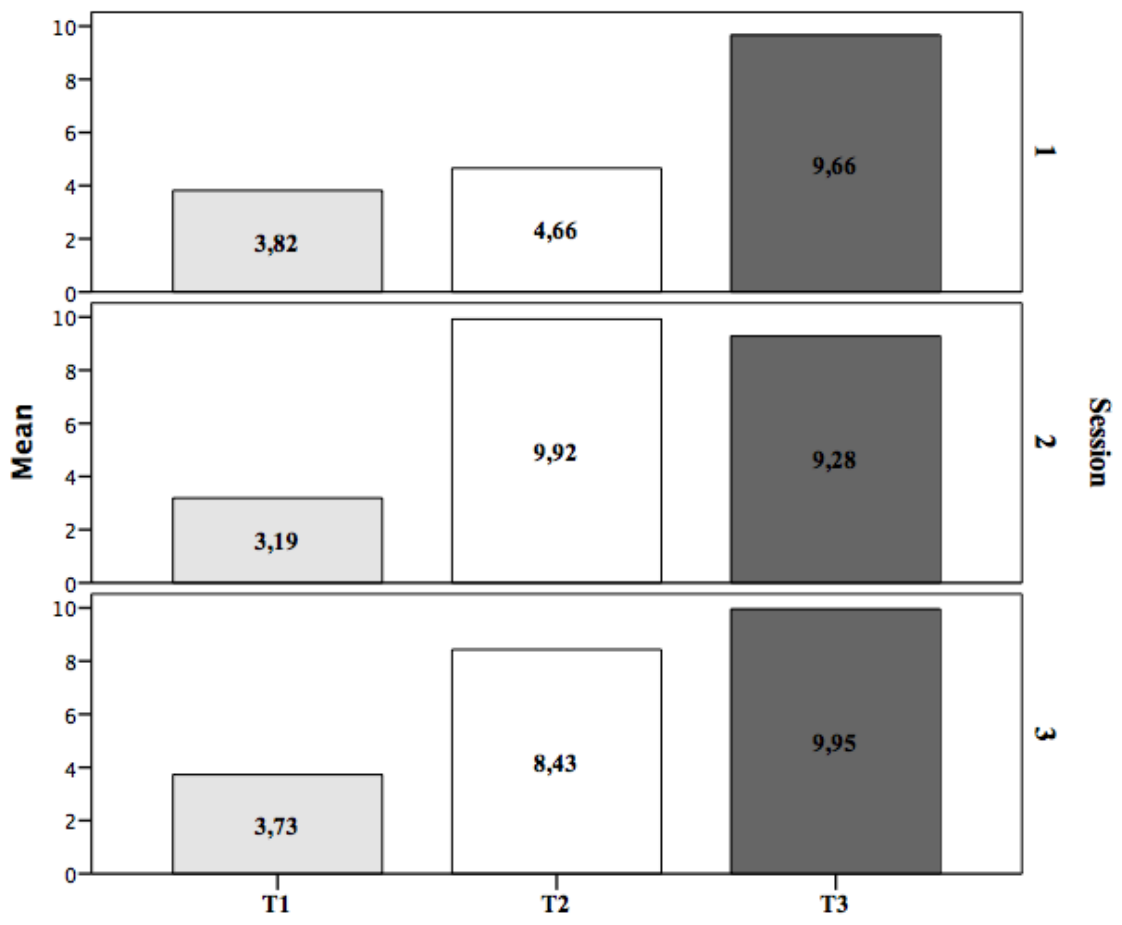

Figure 2: Contribution mean in the $\mathrm{G}$ account by treatment and session Source: Research Data.

Thus, even in the absence of any formal mechanism of regulation that would "force" individuals to contribute for the existence of a factor, which would diminish their benefit due to opportunistic action, even then it is possible to verify that cooperation was possible. It was possible because individuals presented a high capacity to self-organize by the presence of social pressure, social norms and increased group cohesion, creating a trustworthiness environment, which enabled cooperation to happen.

Such a claim can be best supported by the analysis of the transcription of the recorded discussions between the participants of the group. By the recorded communication, it was possible to observe a great concern from individuals in finding a joint solution for the problem they faced. In the same way, we observed a great necessity to discover and pressure those who were not fulfilling their promise to cooperate (even though it would not be possible to discover which player was acting opportunistically).

The idea that if everyone cooperated, joint earnings would be higher and yield better benefits for all, was constantly emphasized. Similarly, trust was often stressed. Several times, different participants recalled that, in the case that a persistent opportunistic behavior by other players was perceived, trust would be "broken" and they would cheat too, leading the group as a whole to a much lower joint result. 
In the last treatment in $\mathrm{S} 2(\mathrm{C} / \mathrm{P} M=2)$, the levels of cooperation remained high. However, the difference in contributions between the $2^{\text {nd }}$ and $3^{\text {rd }}$ treatments (from 9.92 to 9.28) is not significant (Wilcoxon, $\mathrm{p}=0.180$ ). Nonetheless, the variation of contributions $\left(\mathrm{s}_{2}^{2}=0.018\right.$ and $\left.\mathrm{s}_{3}^{2}=0.421\right)$ increased (Levene, $\left.\mathrm{p}=0.002\right)$. In this way, even if the contributions mean have not changed, the stability of cooperation was impaired and, in fact, by observing Figure 1, there is a higher oscillation from contributions in relation to the $2^{\text {nd }}$ treatment.

From the conversations recorded during the times of communication in this $3^{\text {rd }}$ treatment, it was possible noticing that the inclusion of the formal mechanism destabilized cooperation between them. A particular distrust spread among the members of the group, at which point some started to look for a "loophole", which if detected, could increase the benefits earned by the player. This explains, in large part, the reason for the higher oscillation in contributions in the first three periods of this $3^{\text {rd }}$ treatment, as can be seen in Figure 1.

Considering that there was no increase in the contributions between the $2^{\text {nd }}$ and $3^{\text {rd }}$ treatments in this session 2 and, in sessions 1 and 3, the inclusion of communication in the third treatment increased contribution levels in relation to the second treatment $(\mathrm{CN} / \mathrm{P})$, in the aggregate, these results support H2, as shown in Figure 2.

Finally, when comparing the $3^{\text {rd }}$ treatment among all sessions, when both formal and informal mechanisms were present, there is no significant difference between contributions (Kruskal-Wallis, $\mathrm{p}=0.641$ ).

\section{DISCUSSION}

Based on these results, we can argue that in the absence of a regulatory mechanism (be it formal or informal), the propensity to cooperate decreases over time, in other words, the agents are not able to reach a satisfactory solution for the group, succumbing to the proposed problem.

As predicted by theory, by introducing the formal contract, the results corroborate the argument that the formal incentive may be a possible mechanism to curb the downward trend of cooperation. However, it is worth emphasizing the differences in results that were found in the variations of the formal contract. When this factor presented a low capacity $(M=0.5)$ to sanction defection, cooperation levels were significantly lower than in the situation in which the factor was strong. Based on this finding, one can question whether the application of a weak formal mechanism is useful - given the costs of implementation and the possible side 
effects that it entails - since it presents itself as relatively inefficient with respect to ensuring an optimal level of cooperation in the group.

The informal arrangement produced higher levels of cooperation, when compared to the levels achieved by the formal contract, even when the punishment factor was strong. These results show that agents can cooperate, even when they are not under any formal constrain to cooperate due to the concern of having their payoffs penalized. By the recorded discussions between the group members, we observe that elements such as trust, reciprocity, social norms and social pressures played an important role in increasing cooperation, even when individual interests are in conflict with the collective interest of the group.

Regarding the joint effect of formal and informal contracts, we propose that the interaction of substitutes or complements is dependent on the timing of the constitution of each contract. When cooperation among agents had already been established via informal arrangements, the posterior application of formal contracts did not alter the level of cooperation among agents. However, there was an increase in the variance of contributions, suggesting that the inclusion of the formal mechanism generated noise in the cooperation among agents. Based on this, we can argue that when the agents are already able to cooperate via informal arrangements, the constitution of formal incentives may cause some weakening (at least with regard to stability) of cooperation, suggesting a possible substitution effect.

However, when the informal arrangement was inserted after the formal one, we observed an improvement in cooperaton levels when compared with both the weak $(M=0.5)$ formal sanction as well as the strong one $(M=2)$. Furthermore, in the presence of the informal arrangement, variations in the intensity of the penalty/reward factor $(M=0.5$ or 2$)$ did not present differences in contributions levels any longer. Thus, we can argue that the informal arrangement was able to minimize differences in contributions levels between strong and weak contracts, indicating that the great mediator of the cooperative decision was the informal contract.

Thus, in the prior existence of a formal agreement, the posterior development of informal arrangements is able to further increase the levels of cooperation among agents, indicating a possible complementary effect.

\subsection{MANAGERIAL IMPLICATIONS}

Some practical considerations can be drawn from this study related to the design of incentives and contracts between firms (strategic alliances, for example). First, despite the fact 
that the formal contract is seen as the most effective mechanism to inhibit opportunism in transactions, the results of this study suggest that informal arrangements can be quite effective to leverage cooperation, without incurring the tangible (implementation and monitoring costs) and intangible (signaling a lack of trust) costs of formal contracts. However, this understanding of the informal agreement as a viable alternative to increase cooperation in transactions does not imply giving up the use of the formal agreement to legally endorse exchanges between firms. There are several attributes of transactions that make the formal contract as the most dominant mechanism in the governance of relationships.

In fact, some previous research (CARSON et al, 2006; DE JONG; WOOLTHUIS; 2009; MELLEWIGT et al, 2007) have pointed out how some transaction attributes such as asset specificity may increase the need for contractual complexity to govern the relationship. Specific assets refer to those ones that are of specialized use to the transaction and, as such, are of little use or value outside of that particular transacting relationship. Aware of this information, the counterpart of the relationship can take advantage of the other's investment in specific assets to increase his bargaining power and renegotiate the terms of the transaction in his favor (WILLIAMSON, 1991). Similarly, any other attribute of the relationship, which reflects information asymmetries and ambiguity (such as intensive knowledge transfer between parties), increases the need for formal clauses to protect intellectual property rights and avoid spill-over risks (confidentiality safeguards). For these reasons, in order to increase the willingness of the parties to incur in the necessary investments to create value in the transaction, it is useful to employ formal contracts with greater contractual complexity, since more specific contractual provisions may facilitate the interpretation and enforcement of the contract, if necessary.

In addition, there are examples where formal agreements have been used more effectively. In general, we can argue that contexts where institutions are stronger provide a more efficient legal system, facilitating the use of formal contracts and increasing the perception of a legitimate and effective mechanism to apply any disciplinary sanctions to opportunistic agents. In fact, some studies (ARON, 2000) indicate that strong formal institutions may improve economic growth via its positive effects on the volume of investment in the country by signaling a lower risk.

For all these reasons, although informal agreements may be an even more effective mechanism than formal agreements to ensure cooperation, we should also consider the 
specific contingencies of the relationship, which may require the use of formal contracts to make some transactions possible.

In addition, the results also suggest that the complementary relationship between formal and informal contracts depends on their order of constitution. Under the same levels of uncertainty and complexity of the transaction, in situations where cooperation is already established via informal arrangement, the posterior use of formal contracts does not add much to the levels of cooperation among agents. In this sense, any increase in contractual complexity should try to incorporate more clarification of roles or other coordination provisions than controls and safeguards against opportunism. However, in situations where cooperation was initially grounded on formal contractual provisions and, subsequently, the informal arrangement develops, both contracts may function as complements. This is due to the fact that such legal protections, derived from the formal contract, make the relationship more stable, allowing partners to invest more time and efforts on activities typical of informal arrangements, such as: coordination activities, joint strategy and learning and adaptation processes that contribute to the collective performance of the partnership.

\subsection{SUGGESTIONS FOR FUTURE RESEARCH}

This study aimed to compare the effectiveness with which formal and informal agreements can influence the decision of cooperation between agents and also investigate the interaction and joint effect of these contracts. Despite the interesting results, there are several research opportunities to further refine the understanding of the topic.

Regarding the formal contract, we can suggest future modifications. In this experiment, it did not entail any cost to the players and their monitoring capacity was perfect. However, in natural environments, sanction systems usually involve some costs associated to their application and maintenance, just as their ability to identify and appropriately punish opportunistic behavior may fail. Thus, the inclusion of these considerations on the design of formal contracts would further enrich the experimental findings.

Another important issue concerns the durability of cooperation resulting from the use of formal and informal contracts. Due to the extent of the current game (which was played for 30 periods), we were not able to include this variable in the experiment. However, in future research, it may be interesting to evaluate the stability of cooperation that formal and informal contracts may produce. In other words, it would be worth applying both contracts and then suspend them after some periods and posteriorly analyze the dynamics of cooperation that follows, when they are no longer present. 


\section{NOTES}

(1) All statistical analyzes were performed using the group as a unit of analysis to minimize the resulting bias from the low variance of contributions over the last treatment of all sessions.

\section{REFERENCES}

AGARWAL, R.; CROSON, R.; MAHONEY, J. T. The role of incentives and communication in strategic alliances: an experimental investigation. Strategic Management Journal, v.31, p.413-437, 2010.

ANTIQUEIRA, J. R. M.; SAES, M. S. M.; LAZZARINI, S. G. Comportamento oportunista em negociações envolvendo ativos específicos: um estudo com metodologia experimental, Revista de Administração RAUSP, v.42, p.393-404, 2007.

ARON, J. Growth and institutions: a review of the evidence. The World Bank Research Observer, v.15, n.1, p.99-135.

BAKER, G.; GIBBONS, R.; MURPHY, K. J. Relational contracts and the theory of the firm. The Quarterly Journal of Economics, v.117, p.39-84, 2002.

BARTLING, B.; FEHR, E.; SCHMIDT, K.M. Screening, competition, and job design: economic origins of good jobs. American Economic Review, v.102, n.2, p.834-864, 2012.

BOLTON, G.; KATOK, E.; OCKENFELS, A. How effective are eletronic reputation mechanisms? An experimental investigation. Management Science, v.50, n.11, p.1587-1602, 2004.

CARSON, S. J.; MADHOK, A.; WU, T. Uncertainty, opportunism, and governance: the effects of volatility and ambiguity on formal and relational contracting. Academy of Management Journal, v.49, n.5, p.1058-1077, 2006.

CIALDINI, R. B. Social influence and the triple tumor structure of organizational dishonesty. In: MESSICK, D. M.; A. E. TENBRUNSEL, A. E. (Eds.), Codes of conduct: behavioral research into business ethics. New York: Russell Sage, 1996.

DAL BÓ, P. Cooperation under the shadow of the future: experimental evidence from infinitely repeated games. The American Economic Review, v.95, n.5, p.1591-1604, 2005.

DAWES, R. M.; MESSICK, D. M. Social dilemmas. International Journal of Psychology, v.35, n.2, p.111-116, 2000.

DE JONG, G.; WOOLTHUIS, R. K. The content and role of formal contracts in high-tech alliances. Innovation: Management, Policy \& Practice, v.11, p.44.59, 2009.

DORE, R. Goodwill and the spirit of market capitalism. The British Journal of Sociology, v.34, n.4, p.459-482, 1983. 
FALK, A.; GATCHER, S.; KOVACS, J. Intrinsic motivation and extrinsic incentives in a repetead game with incomplete contracts. Journal of Economic Psychology, v.20, p.251284, 1999.

FALK, A.; KOSFELD, M. The hidden costs of control. The American Economic Review, v.96, n.5, p.1611-1630, 2006.

FEHR, E.; FISCHBACHER, U. Why social preferences matter: the impact of non-selfish motives on competition, cooperation and incentives. The Economic Journal, v.112, p. 1-33, 2002.

FEHR, E.; SCHMIDT, K. M. Adding a stick to the carrot? The interaction of bonuses and fines. The American Economic Review, v.97, n.2, p.177-181, 2007.

FREY, B. S.; JEGEN, R. Motivation crowding theory. Journal of Economic Surveys, v.15, n.5, p.589-611, 2001.

FISCHBACHER, U. Z-tree: zurich toolbox for ready-made economic experiments. Experimental Economics, 10(2), 171-178, 1999.

GNEEZY, U.; RUSTICHINI, A. Pay enough or don't pay at all. The Quarterly Journal of Economics, v.115, n.3, p.791-810, 2000.

GULATI, R. Social structure and alliance formation patterns: a longitudinal analysis. Administrative Science Quarterly, v.40, p.619-652, 1995.

HARDIN, G. Tragedy of the commons. Science, v.162, p.1243-1248, 1968.

KOLLOCK, P. Social dilemmas: the anatomy of cooperation. Annual Review of Sociology, v.24, p.183-214, 1998.

LAZZARINI, S. G.; MILLER, G. J.; ZENGER, T. R. Order with some law: complementarity versus substitution of formal and informal agreements. Journal of Law, Economics, \& Organization, v.20, n.2, p.261-298, 2004.

MACAULAY, S. Non-contractual relations in business: a preliminary study. American Sociological Review, v.28, n.1, p.55-67, 1963.

MELLEWIGT, T.; MADHOK, A.; WEIBEL, A. Trust and formal contracts in interorganizational relationships: substitutes and complements. Managerial and Decisions Economics, v.28, p.833-847, 2007.

MALHOTRA, D.; MURNIGHAN, J. K. The effects of contracts on interpersonal trust. Administrative Science Quarterly, v.47, p.534-559, 2002.

NORTH, D. Institutions, institutional change and economic performance. Cambridge: Cambridge University Press, 1990.

OSTROM, E. Governing the commons: the evolution of institutions for collective action. Cambridge: Cambridge University Press, 1990. 
OSTROM, E.; WALKER, J.; GARDNER, R. Covenants with and without a sword: selfgovernance is possible. The American Political Science Review, v.86, n.2, p.404-417, 1992.

PARKHE, A. Strategic alliance structuring: a game theoretic and transaction cost examination of interfirm cooperation. Academy of Management Journal, v.36, n.4, p.794-829, 1993.

PFEFFER, J. Competitive advantage through people. Boston: Harvard Business School Press, 1994.

POPPO, L.; ZENGER, T. Do formal contracts and relational governance function as substitutes or complements. Strategic Management Journal, v.23, n.8, p.707-725, 2002.

RING, P. S.; VAN DE VEN, A. H. Developmental processes of cooperative interorganizational relationships. Academy of Management Review, v.19, n.1, p.90-118, 1994.

ROTH, A. Bargaining experiments. In: ROTH, A.; KAGEL, J. (Eds.), Handbook of experimental economics. New Jersey: Princeton University Press, 1995.

ROUSSEAU, D. M., et al. Not so different after all: a cross-discipline view of trust. Academy of Management Review, v.23, n.3, p. 393-404, 1998.

SAUAIA, A. C. A.; ZERRENNER, S. A. Jogos de empresa e economia experimental: um estudo de racionalidade organizacional na tomada de decisão. Revista de Administração Contemporânea, v.13, n.2, p.189-209, 2009.

SITKIN, S. B.; ROTH, N. L. Explaining the limited effectiveness of legalistic remedies for trust/distrust. Organization Science, v.4, n.3, p.367-392, 1993.

TENBRUNSEL, A. E.; MESSICK, D. M. Sanctioning systems, decision frames, and cooperation. Administrative Science Quarterly, v.44, n.4, p.684-707, 1999.

WILLIAMSON, O. E. Comparative economic organization: the analysis of discrete structural alternatives. Administrative Science Quarterly, v.36, p.269-296, 1991.

ZASU, Y. Sanctions by social norms and the law: substitutes or complements? Journal of Legal Studies. v.6, n.2, p.129-166, 2007.

ZENG, M.; CHEN, X. Achieving cooperation in multiparty alliances: a social dilemma approach to partnership management. Academy of Management Review, v.28, n.4, p.587$605,2003$.

ZENGER, T. R.; LAZZARINI, S. G.; POPPO, L. Informal and formal organization in new institutional economics. In: INGRAM, P; SILVERMAN, B. (Eds.), The new institutionalism in strategic management. Elsevier Science, 2002. 